\title{
PENGUKURAN LAJU PAPARAN RADIASI PADA RUANG CT-SCAN
}

\author{
Devi Febriana Putri ${ }^{1)}$ Sudiyono ${ }^{2)}$ \\ ${ }^{1}$ PKU Sukoharjo. \\ ${ }^{2}$ Poltekkes Kemenkes Semarang \\ Mail : dfebriana50@gmail.com
}

\begin{abstract}
Background : CT-Scan is an imaging modality in the field of diagnostics, especially radiology that produces large radiation, so should pay attention to aspects of protection and radiation safety for radiographers and public. At the CT-Scan examination room at Radiology Installation of RSUD Ir. Soekarno has made door replacement and addition of $2 \mathrm{~mm} \mathrm{~Pb}$ on the window and has not done measurement of exposure rate of re-radiation. This study aims to determine the value of the radiation exposure rate and the safety of the examination room on radiation exposure for radiographers and public reffering to the publication of NCRP no. 147 on the design of protective structures for health facilities

Methods: This type of research is quantitative with survey approach. This research was conducted in May 2018. Data collection was done by observation, documentation, measurement of exposure rate at a number of points. Data analysis was done descriptively by comparing data with NCRP report no 147.

Result: The radiation exposure measurements resulted in excessive radiation exposure in the controlled area at point $\mathrm{A}$ (the $\mathrm{Pb}$ glass in the operator's room) of $29,5 \mu \mathrm{Sv} / \mathrm{h}$ the uncontrolled area at point 1 (patien's entrance) of $1,75 \mu \mathrm{Sv} / \mathrm{h}$. This value exceeds the recommendation value of NCRP no. 147 at controlled area of $2,5 \mu \mathrm{Sv} / \mathrm{h}$ and uncontrolled area of $0,5 \mu \mathrm{Sv} / \mathrm{h}$. Radiology Installation Ir. Soekarno Sukoharjo Hospital regency is located at an altitude of $103 \mathrm{mdpl}$ the background radiation exposure value of $1,225 \mu \mathrm{Sv} / \mathrm{h}$, it exceeds the requirements of the background exposure rate value according to UNSCEAR for a height of 0 meters from sea level is $0.03 \mu \mathrm{Gy} / \mathrm{h}$. Leakage of radiation exposure occurring at point
\end{abstract}

Conclution: point A isa $\mathrm{Pb}$ glass in the operator's room and at point 1 is patien's entrance is not safe for radiographers and public because it exceeds the limit of radiation exposure rate value which is allowed

Keyword : Radiation exposure rate, Measurement, CT-Scan room, Ir. Soekarno Sukoharjo hospital

\section{Pendahuluan}

Instalasi radiologi merupakan sarana penunjang di rumah sakit yang memberikan layanan pemeriksaan radiologi dengan hasil pemeriksaan berupa foto atau gambar dengan menggunakan dan memanfaatkan peralatan sinar-X, untuk menegakkan diagnosa suatu penyakit. Sinar-X termasuk jenis radiasi peng-ion. Menurut Badan Tenaga Nuklir Nasional radiasi adalah energi yang dipancarkan dalam bentuk partikel atau gelombang yang mampu mengionisasi medium yang dilaluinya. Manfaat radiasi peng-ion sangat banyak terutama dibidang industri dan kesehatan. Pada bidang kesehatan, radiasi pengion yang dimanfaatkan adalah sinar-X dan sinar gamma. Sumber radiasi pengion dari sinar$\mathrm{X}$ adalah dari tabung sinar-X. Pemanfaatan sinar- $\mathrm{X}$ umumnya untuk penunjang pencitraan diagnostik. Peralatan yang menghasilkan sinar-X untuk keperluan diagnosa medis antara lain pesawat sinar-X konvensional, pesawat fluoroscopy, pesawat mammografi, pesawat dental (intraoral), pesawat panoramik (ekstraoral) dan Computed Tomography Scan (CT-Scan) (Haditjahyono, 2006).
Paparan radiasi adalah penyinaran radiasi yang diterima oleh manusia atau materi, baik sengaja atau tidak. Oleh sebab itu perlu diadakan suatu upaya untuk mengurangi penerimaan radiasi yaitu proteksi radiasi. Menurut Akhadi (2000), keselamatan radiasi atau proteksi radiasi merupakan suatu cabang ilmu pengetahuan atau teknik yang mempelajari masalah kesehatan manusia ataupun lingkungan dan berkaitan dengan pemberian perlindungan kepada seseorang atau sekelompok orang ataupun kepada keturunannya terhadap kemungkinan yang merugikan kesehatan akibat paparan radiasi. Tujuan proteksi radiasi yaitu untuk mencegah terjadinya efek deterministik dan mengurangi terjadinya efek stokastik serendah mungkin. Menurut Perka BAPETEN No. 8 tahun 2011, pemegang izin sesuai dengan ketentuan yang berlaku wajib menyediakan, melaksanakan, mendokumentasikan program proteksi radiasi dan keselamatan radiasi. Petugas proteksi radiasi mempunyai kewajiban menyusun program proteksi radiasi untuk menekan serendah mungkin kemungkinan terjadinya kecelakaan radiasi. 
Berdasarkan Perka BAPETEN No. 8 tahun 2011 tentang Keselamatan Radiasi Dalam Penggunaan Pesawat Sinar-X Radiologi Diagnostik dan Radiologi Intervensional perlu dilakukan pemantauan radiasi secara rutin atau berkala agar NBD (Nilai Batas Dosis) yang diterima oleh pekerja radiasi tidak terlampaui. NBD (Nilai Batas Dosis) adalah dosis terbesar yang dizinkan oleh BAPETEN yang dapat diterima oleh pekerja radiasi dan anggota masyarakat dalam jangka waktu tertentu tanpa menimbulkan efek genetik dan somatik yang berarti akibat pemanfaatan tenaga nuklir. Maka dalam mengoperasikan sinar-X suatu instalasi radiologi harus menyelenggarakan pemantauan paparan radiasi dengan surveymeter, melakukan pemantauan dosis dan menyediakan perlengkapan proteksi radiasi. Surveymeter adalah alat ukur untuk mengetahui radiasi yang diterima manusia atau materi persatuan jam.

Menurut Perka BAPETEN No. 8 tahun 2011 pemantauan paparan radiasi dilakukan pada fasilitas yang baru dimiliki sebelum digunakan dan fasilitas yang mengalami perubahan serta dilakukan secara periodik. Periode pemantauan laju paparan radiasi pada daerah kerja radiasi untuk diagnostik dilakukan satu kali setahun untuk pemantauan rutin dan harus dilaporkan kepada kepala BAPETEN dengan laporan secara tertulis. Pemantauan daerah kerja radiasi untuk diagnostik merupakan salah satu program proteksi radiasi yang harus dilakukan dalam setiap kegiatan pemantauan tenaga nuklir. Pemantauan daerah kerja radiasi untuk diagnostik dimaksudkan untuk meyakinkan bahwa setiap individu pekerja radiasi terjamin keselamatannya dari bahaya radiasi (Akhadi, 2000). Pemantauan individu digunakan untuk memverifikasi efektivitas pengendalian radiasi di tempat kerja. Hal ini juga digunakan untuk mendeteksi perubahan di tempat kerja, mengkonfirmasi atau melengkapi pemantauan di tempat kerja, mengidentifikasi praktik kerja dengan mengetahui dosis dan memberikan informasi jika terjadi kecelakaan.

Desain bangunan fasilitas pesawat sinar- $\mathrm{X}$ berdasarkan Peraturan Kepala BAPETEN No. 8 Tahun 2011 pasal 57 ayat 3 (c) harus mempertimbangkan beban kerja maksimum, faktor guna penahan radiasi dan faktor penempatan daerah sekitar fasilitas. Dinding ruangan untuk semua jenis pesawat sinar-X terbuat dari bata merah ketebalan 25 $\mathrm{cm}$ atau beton dengan kerapatan jenis $2,2 \mathrm{~g} / \mathrm{cm} 3$ dengan ketebalan $20 \mathrm{~cm}$ atau setara dengan $2 \mathrm{~mm}$ timah hitam $(\mathrm{Pb})$ dan pintu ruangan pesawat sinar- $\mathrm{X}$ harus dilapisi dengan timah hitam dengan ketebalan tertentu, apabila ruangan memiliki jendela, maka jendela ruangan paling kurang terletak pada ketinggian 2 meter dari lantai. CT-Scan merupakan modalitas imaging di bidang diagnostik khususnya radiologi yang memanfaatkan sumber radiasi yang besar, sehingga harus memperhatikan aspek proteksi dan keselamatan radiasi bagi pekerja radiasi dan masyarakat.

Instalasi Radiologi RSUD Ir. Soekarno Sukoharjo memiliki 5 ruang pemeriksaan yang terdiri dari 1 ruang pemeriksaan berisi pesawat sinar-X konvensional, 1 ruang pemeriksaan berisi pesawat Digital Radiography (DR), 1 ruang pemeriksaan yang berisi pesawat panoramic dan $\mathrm{x}$-ray mobile, 1 ruang berisi pesawat CT-Scan dan 1 ruang untuk pemeriksaan USG. Berdasarkan studi pendahuluan dan studi dokumen penulis pada PKL III pada ruang operator pemeriksaan CT-Scan telah dilakukan pengukuran laju paparan pada tanggal 9 Agustus 2017 oleh BAPETEN. Hasil pengukuran laju paparan radiasi dinyatakan terdapat paparan berlebih di luar pintu pemeriksaan sebesar $80 \mu \mathrm{Sv} / \mathrm{jam}$ dan 7 $\mu \mathrm{Sv} /$ jam. Kemudian untuk menindaklanjuti hal tersebut pada bulan Februari 2018 telah dilakukan penggantian pintu masuk utama dan pelapisan timbal $2 \mathrm{~mm}$ pada jendela di atas pintu masuk utama pada ruang pemeriksaan CT-Scan dan belum dilakukan pengukuran laju paparan radiasi ulang.

Berdasarkan latar belakang tersebut penulis tertarik untuk melakukan penelitian dengan judul "PENGUKURAN LAJU PAPARAN RADIASI PADA RUANG CT-SCAN DI INSTALASI RADIOLOGI Ir. SOEKARNO KABUPATEN SUKOHARJO".

\section{Metode}

Jenis penelitian ini adalah penelitian kuantitatif deskriptif dengan pendekatan observasional. Penelitian ini dilakukan di ruang pemeriksaan CTScan Instalasi Radiologi RSUD Ir. Soekarno Kabupaten Sukoharjo. Cara memperoleh data yaitu dengan observasi, pengukuran dan dokumentasi. Pengolahan data dari pengukuran laju paparan radiasi pada titik-titik yang telah ditentukan sebelumnya sebanyak 3 kali, lalu di buat rata-rata dari hasil 3 kali pengukuran untuk mengetahui besar laju paparan radiasi pada titik-titik tersebut. Hasil pengukuran laju paparan kemudian dikurangi paparan latar untuk mendapatkan laju paparan radiasi sesungguhnya. Data hasil pengukuran kemudian disajikan dalam bentuk tabel. Analisis data untuk mengetahui tingkat keamanan ruangan pemeriksaan dilakukan dengan cara membandingkan data yang diperoleh dari hasil pengukuran dengan NCRP Report No. 147 dan dilakukan penarikan kesimpulan.

\section{Hasil dan Pembahasan}

Penelitian ini dilaksanakan secara langsung oleh penulis di daerah terkontrol dan daerah tidak terkontrol pada ruang pemeriksaan CT-Scan di Instalasi Radiologi RSUD Ir. Soekarno Kabupaten Sukoharjo. Penulis telah melakukan observasi pada ruang pemeriksaan CT-Scan di Instalasi Radiologi RSUD Ir. Soekarno Kabupaten Sukoharjo, berdasarkan hasil observasi RSUD Ir. Soekarno Kabupaten Sukoharjo terletak pada ketinggian 103 m 


\begin{tabular}{|c|c|c|c|c|c|}
\hline $\mathrm{a}$ & : & Ruang Logistik & $\mathrm{j}$ & : & $\begin{array}{l}\text { Ruang Ganti } \\
\text { Pasien }\end{array}$ \\
\hline b & : & Ruang USG & $\mathrm{k}$ & $:$ & $\begin{array}{l}\text { Kamar Mandi } \\
\text { Pasien }\end{array}$ \\
\hline $\mathrm{c}$ & & Ruang Arsip & 1 & : & $\begin{array}{l}\text { Ruang } \\
\text { Pemeriksaan } 1\end{array}$ \\
\hline $\mathrm{d}$ & : & Ruang Jaga & $\mathrm{m}$ & : & $\begin{array}{l}\text { Ruang } \\
\text { Pemeriksaan } 2\end{array}$ \\
\hline e & & $\begin{array}{l}\text { Ruang } \\
\text { Ekspertise } \\
\text { Dokter }\end{array}$ & $\mathrm{n}$ & : & $\begin{array}{l}\text { Ruang } \\
\text { Pemeriksaan } 3\end{array}$ \\
\hline $\mathrm{f}$ & & $\begin{array}{l}\text { Kamar Mandi } \\
\text { Petugas }\end{array}$ & o & : & $\begin{array}{l}\text { Instalasi Gawat } \\
\text { Darurat (IGD) }\end{array}$ \\
\hline $\mathrm{g}$ & & Ruang Logistik & $\mathrm{p}$ & : & $\begin{array}{l}\text { Ruang Dokter } \\
\text { Muda }\end{array}$ \\
\hline h & & $\begin{array}{l}\text { Ruang } \\
\text { Pengolah Citra }\end{array}$ & $\mathrm{Q}$ & $:$ & $\begin{array}{l}\text { Ruang } \\
\text { Pemeriksaan } \\
\text { CT-Scan }\end{array}$ \\
\hline i & & $\begin{array}{l}\text { Ruang } \\
\text { Administrasi }\end{array}$ & & & \\
\hline
\end{tabular}

diatas permukaan laut. Letak Instalasi Radiologi RSUD Ir. Soekarno Kabupaten Sukoharjo terhadap daerah sekitarnya yaitu, sebelah barat bersebelahan dengan jalan umum, sebelah timur bersebelahan dengan Instalasi Gawat Darurat (IGD) dan laboratorium, sebelah utara bersebelahan dengan jalan umum yang menghubungkan antara ruang CTScan dengan ruang rawat inap, sebelah selatan bersebelahan dengan ruang elektromedik yang dipisahkan oleh jalan umum.

Instalasi Radiologi RSUD Ir. Soekarno Kabupaten Sukoharjo memiliki 3 ruang pemeriksaan konvensional, satu ruang pemeriksaan USG dan satu ruang pemeriksaan CT-Scan. Ruang 1 merupakan ruang konvensional untuk pemeriksaan kontras, ruang 2 merupakan ruang Digital Radiography (DR) untuk pemeriksaan non kontras, ruang 3 merupakan ruang konvensional untuk pemeriksaan non kontras untuk pasien ruangan dan satu ruangan USG. Ruang pemeriksaan CT-Scan terpisah dengan ruang pemeriksaan konvensional yang dihubungkan dengan jalan umum. Berikut adalah denah Instalasi Radiologi RSUD Ir. Soekarno Kabupaten Sukoharjo:

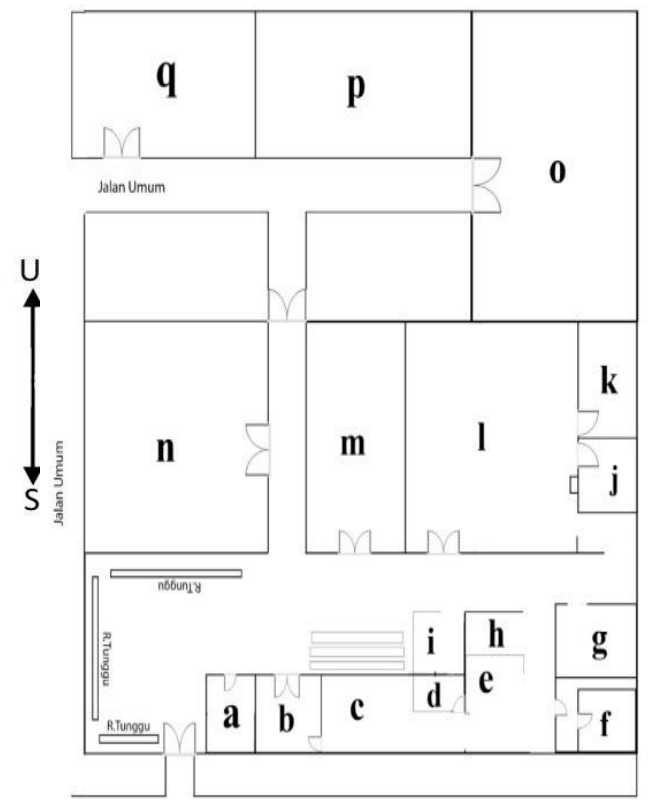

Gambar 4.1 Denah Instalasi Radiologi RSUD Ir. Soekarno Kabupaten Sukoharjo

Keterangan:

Penulis melakukan observasi terhadap karakteristik ruang pemeriksaan CT-Scan di Instalasi Radiologi RSUD Ir. Soekarno Kabupaten Sukoharjo untuk melengkapi data penulis. Karakteristik ruang pemeriksaan CT-Scan di Instalasi Radiologi RSUD Ir. Soekarno kabupaten Sukoharjo, didapatkan data sebagai berikut:

Tabel 4.1 karakteristik struktur ruang pemeriksaan CT-Scan di Instalasi Radiologi RSUD Ir. Soekarno Kabupaten Sukoharjo

\begin{tabular}{|c|c|}
\hline $\begin{array}{l}\text { Karakteristik } \\
\text { Struktur Ruang CT- } \\
\text { Scan }\end{array}$ & Keterangan \\
\hline Dimensi Ukuran & $\begin{array}{l}\text { Panjang } 8 \mathrm{~m} \times \text { Lebar } 4 \mathrm{~m} \times \\
\text { Tinggi } 3,3 \mathrm{~m}\end{array}$ \\
\hline Dinding & \\
\hline Ketebalan Dinding & $30 \mathrm{~cm}$ beton \\
\hline Tinggi Dinding & 3,3 m dari permukaan lantai \\
\hline Pelapis $\mathrm{Pb}$ & $0,25 \mathrm{~mm} \mathrm{~Pb}$ \\
\hline Pintu : & \\
\hline Jenis pintu & Pintu Dorong \\
\hline Ukuran Pintu & Lebar $1,4 \mathrm{~m} \mathrm{x}$ tinggi $2 \mathrm{~m}$ \\
\hline Bahan Pintu & Plat Besi $+2 \mathrm{~mm} \mathrm{~Pb}$ \\
\hline Tabir: & \\
\hline Tebal kaca intip $\mathrm{Pb}$ & $1,5 \mathrm{~mm} \mathrm{~Pb}$ \\
\hline
\end{tabular}

a. Unit Peralatan Sinar-X

Instalasi Radiologi RSUD Ir. Soekarno Kabupaten Sukoharjo memiliki satu buah pesawat CT-Scan. Adapun spesifikasi dari pesawat sinar$\mathrm{X}$ adalah sebagai berikut:

\begin{tabular}{ll} 
Nama Alat & : CT-Scan \\
Merk & : Hitachi \\
Model/Type & : ECLOS-16 \\
No. Seri Sistem & $:$ E1418 \\
Tahun Pembuatan & $: 2011$ \\
Merk & $:$ Varriant \\
Type Tube & $:$ B-421H \\
No. Seri Tube & $:$ H80005 \\
Type Insert Tube & $:$ GS-4570 \\
No. Seri Insert Tube & $:$ 80005-N7 \\
\multicolumn{1}{c}{ Berikut adalah } & gambar den \\
pemeriksaan CT-Scan : &
\end{tabular}

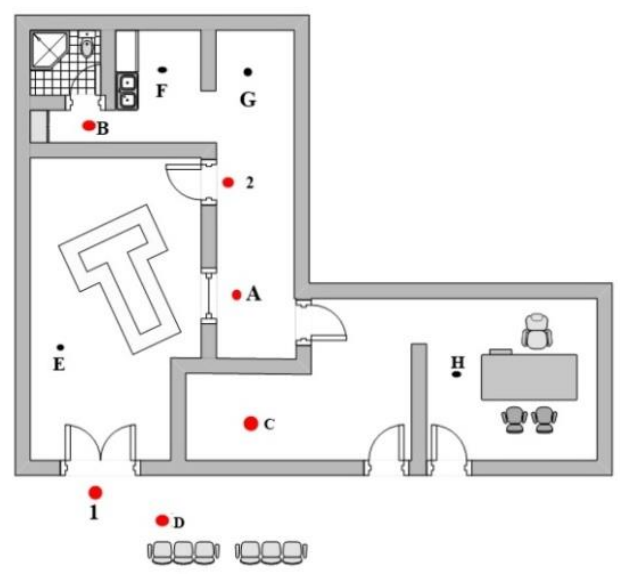


Gambar 4.2 Denah ruang pemeriksaan CT-Scan Keterangan :

: Titik Pengukuran

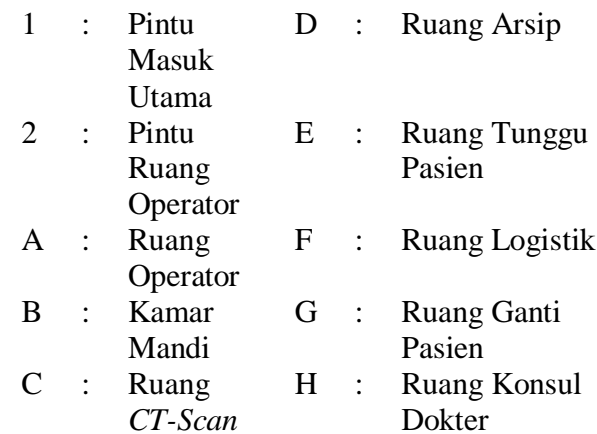

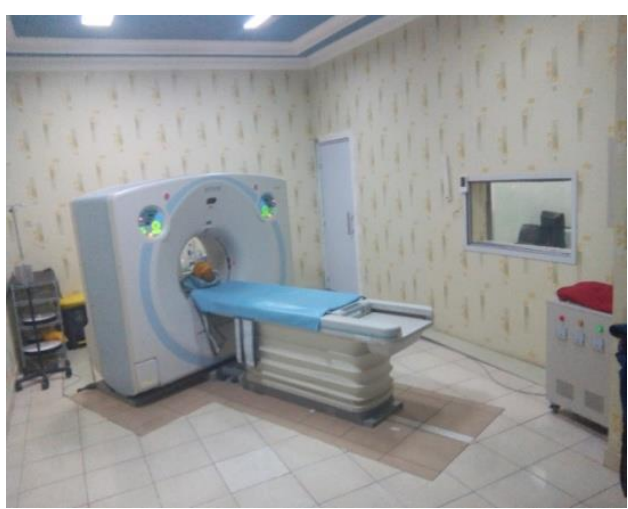

Gambar 4.3 ruang pemeriksaan CT-Scan

Adapun spesifikasi alat ukur yang digunakan untuk pengukuran laju paparan radiasi di ruang CT-Scan adalah sebagai berikut :

$\begin{array}{ll}\text { Nama/ Jenis Alat } & \text { : Surveymeter Gamma } \\ \text { Model/Type } & \text { : Babyline } \\ \text { No. Seri } & : 81 \mathrm{Sn} / 3933 \\ \text { Pabrik } & : \text { Canberra }\end{array}$

Tanggal surat kalibrasi : 1 Februari 2018

Factor kalibrasi $\quad: 100 \mu \mathrm{Gy} / \mathrm{jam} \quad: 1,05$ $1000 \mu \mathrm{Gy} / \mathrm{jam} \quad: 0,95$

Berikut adalah gambar alat ukur yang digunakan untuk pengukuran laju paparan radiasi di ruang CT-Scan din Instalasi Radiologi RSUD Ir. Soekarno Kabupaten Sukoharjo:

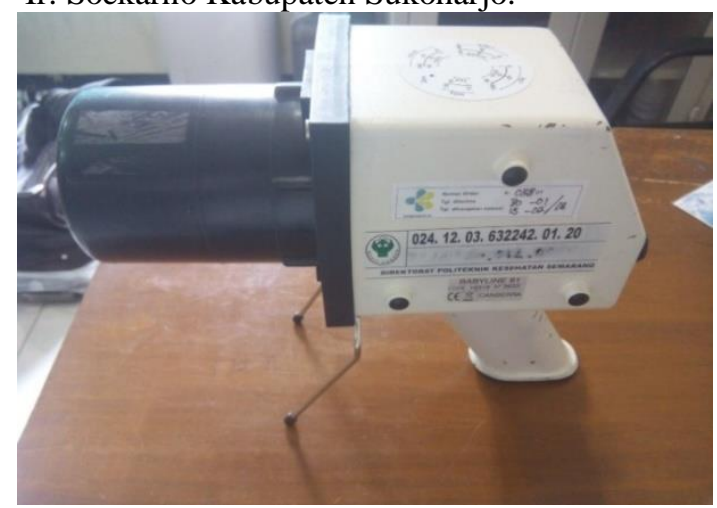

Gambar 4.4 Alat Ukur Surveymeter Babyline
1. Prosedur pengukuran laju paparan radiasi pada Ruang CT-Scan di Instalasi Radiologi RSUD Ir. Soekarno Kabupaten Sukoharjo

Penulis melakukan observasi terhadap karakteristik ruangan CT-Scan meliputi dimensi ukuran, dinding, pintu, tabir, kaca intip dan tanda radiasi. Penulis menyiapkan surveymeter babyline untuk mengukur laju paparan radiasi guna mengetahui terdapat atau tidaknya laju paparan radiasi di ruang pemeriksaan CT-Scan di Instalasi Radiologi RSUD Ir. Soekarno Kabupaten Sukoharjo, sebelum melakukan pengukuran dengan menggunakan surveymeter babyline penulis melakukan pengecekan alat ukur dengan beberapa langkah antara lain sebagai berikut :

a. Memeriksa baterai, penulis memasang baterai sesuai dengan tanda positif dan negative yang berada pada surveymeter.

Mengatur skala pengukuran, penulis

b. mengatur skala pengukuran yaitu $100 \mu \mathrm{Gy} / \mathrm{h}$ dengan faktor kalibrasi 1,05.

c. Memutar tombol dari 0 ke Test pada surveymeter untuk mengetahui kondisi baterai dalam keadaan baik atau tidak.

d. Baterai dengan keadaan baik ditandai dengan bergeraknya jarum surveymeter menuju area hitam pada layar surveymeter, apabila jarum surveymeter bergerak namun tidak sampai pada rentang area hitam pada layar surveymeter maka baterai yang digunakan perlu diganti yang baru.

e. Memeriksa sertifikat kalibrasi, penulis memeriksa sertifikat kalibrasi surveymeter. Alat yang digunakan penulis yaitu surveymeter babyline tercatat telah dilakukan kalibarasi pada tanggal 1 Februari 2018.

Pengukuran laju paparan radiasi dilaksanakan setelah pengecekan alat selesai beberapa langkah pengukuran laju paparan radiasi antara lain :

a. Mengukur jarak setiap titik terhadap sumber radiasi.

b. Melakukan pengukuran laju paparan radiasi latar (background) di setiap titik yang sudah ditentukan pada ruang pemeriksaan CTScan sebelum dilakukan ekspose.

c. Mengatur phantom pada meja pemeriksaan.

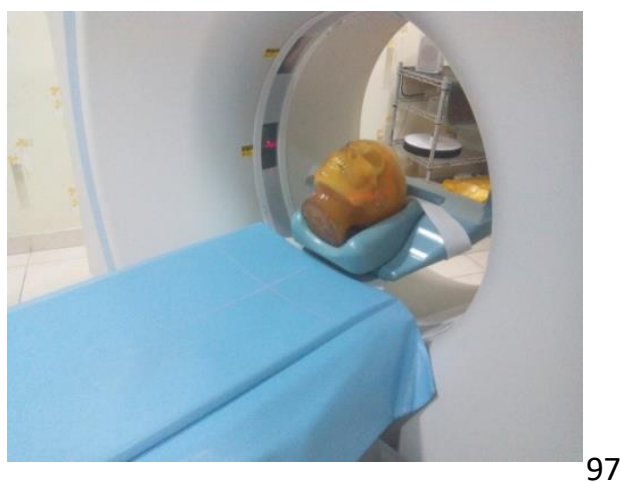


Gambar 4.5 Pengaturan phantom pada meja pemeriksaan

d. Mengatur faktor ekspose atau scan parameter

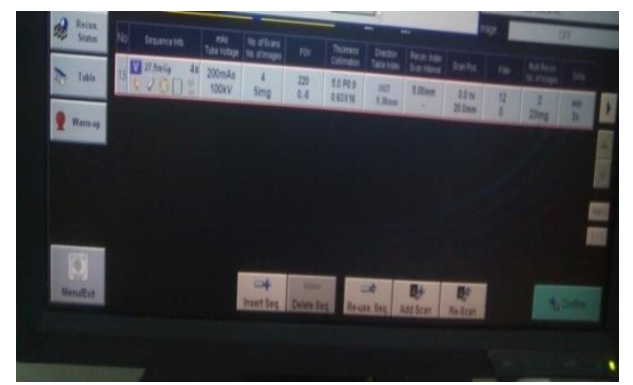

Gambar 4.6 Scan parameter pemeriksaan CTScan kepala yaitu kV 100, mA 250 dan s 0,8

e. Melakukan pengukuran pada lokasi pengukuran disetiap titik pengukuran

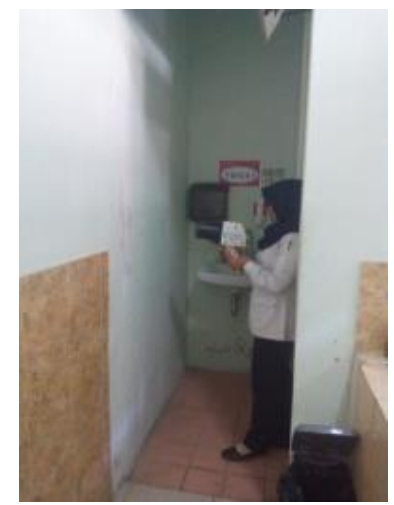

Gambar 4.7 pengukuran pada titik pengukuran kamar mandi pasien

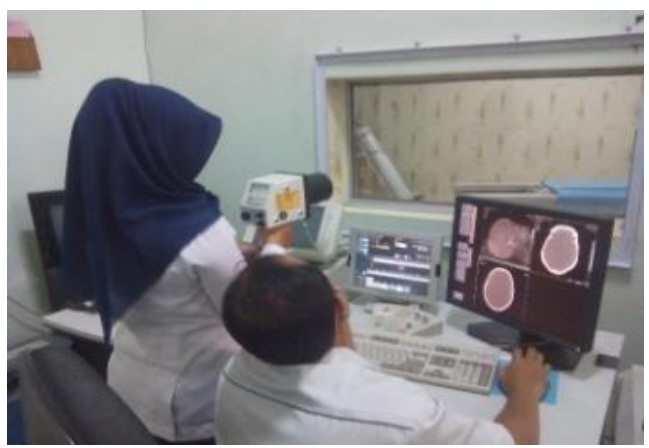

Gambar 4.8 pengukuran pada titik pengukuran ruang operator

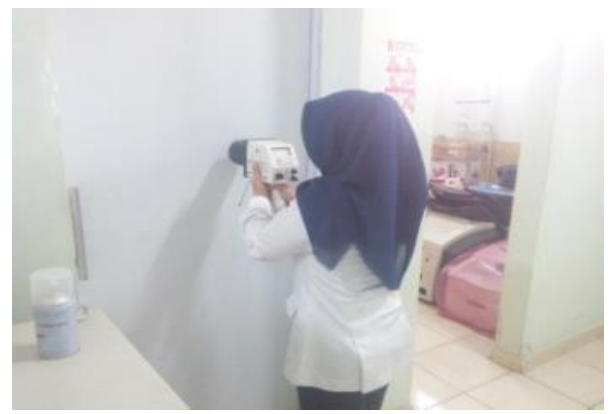

Gambar 4.9 pengukuran pada titik pengukuran pintu masuk dari ruang operator

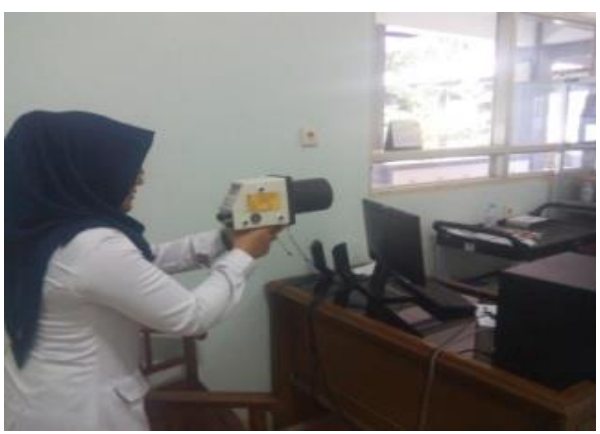

Gambar 4.10 pengukuran pada titik pengukuran ruang arsip

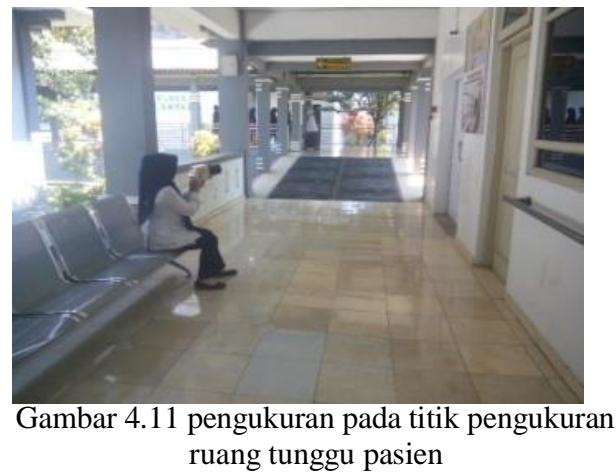

2. Hasil pengukuran laju paparan radiasi pada Ruang CT-Scan di Instalasi Radiologi RSUD Ir. Soekarno Kabupaten Sukoharjo

Pengukuran laju paparan radiasi dilakukan pada titik-titik yang telah ditentukan sebelumnya dan sesuai dengan langkah-langkah penelitian. Alat ukur yang digunakan untuk pengukuran laju paparan adalah surveymeter babyline. Pengukuran dilakukan sebelum ekspose yang dimaksudkan untuk mengukur nilai paparan radiasi latar (background) dan saat ekspose dimaksudkan untuk mengetahui nilai paparan radiasi setelah melewati perisai.

Pengukuran laju paparan radiasi dilakukan dengan menggunakan faktor ekspose pada pemeriksaan CT-Scan kepala yaitu kV 100, mA 250 dan s 0,8 . Jarak titik pengukuran dengan sumber radiasi bervariasi. Pada saat pengukuran laju paparan radiasi digunakan objek berupa phantom cranium untuk mensimulasikan radiasi hambur pada saat ekspose. Hasil bacaan yang didapatkan dari surveymeter babyline yaitu dalam satuan $\mu \mathrm{Gy} / \mathrm{jam}$ yang dikonversikan menjadi $\mu$ Sv/jam, untuk mendapatkan hasil bacaan surveymeter yang sebenarnya, hasil pada surveymeter dikalikan dengan skala yang digunakan yaitu $100 \mu \mathrm{Gy} / \mathrm{h}$ dan faktor kalibrasinya yaitu 1,05 .

Hasil pengukuran laju paparan radiasi disajikan dalam bentuk tabel sebagai berikut : 
Tabel 4.2 Nilai pengukuran laju paparan radiasi

\begin{tabular}{|c|c|c|c|c|c|}
\hline No & $\begin{array}{c}\text { Titik } \\
\text { Penguku } \\
\text { ran }\end{array}$ & $\begin{array}{c}\text { Jarak } \\
\text { dari } \\
\text { sumber } \\
\text { radiasi }\end{array}$ & $\begin{array}{c}\text { Backg } \\
\text { round } \\
(\mu \mathrm{Sv} / \mathrm{h} \\
)\end{array}$ & $\begin{array}{c}\text { Laju } \\
\text { papara } \\
\text { n } \\
\text { radiasi } \\
(\mu \mathrm{Sv} / \mathrm{h} \\
)\end{array}$ & $\begin{array}{c}\text { Hasil } \\
\text { ukur } \\
\text { sebena } \\
\text { r-nya } \\
(\mu \mathrm{Sv} / \mathrm{h} \\
)\end{array}$ \\
\hline 1. & $\begin{array}{l}\text { Pintu } \\
\text { masuk } \\
\text { dari } \\
\text { ruang } \\
\text { operator } \\
(2)\end{array}$ & $4,33 \mathrm{~m}$ & 1,05 & 1,05 & 0 \\
\hline 2. & $\begin{array}{l}\text { Kaca } \mathrm{Pb} \\
\text { ruang } \\
\text { operator } \\
\text { (A) }\end{array}$ & $2,9 \mathrm{~m}$ & 2,1 & 31,6 & 29,5 \\
\hline 3. & $\begin{array}{l}\text { Kamar } \\
\text { mandi } \\
\text { (B) }\end{array}$ & $3 \mathrm{~m}$ & 1,05 & 1,05 & 0 \\
\hline 4. & $\begin{array}{l}\text { Ruang } \\
\operatorname{arsip}(\mathrm{C})\end{array}$ & $5,25 \mathrm{~m}$ & 1,05 & 1,05 & 0 \\
\hline 5. & $\begin{array}{l}\text { Pintu } \\
\text { pasien } \\
\text { (1) }\end{array}$ & $5 \mathrm{~m}$ & 1,05 & 1,4 & 0,35 \\
\hline 6. & $\begin{array}{l}\text { Ruang } \\
\text { tunggu } \\
\text { pasien } \\
\text { (D) }\end{array}$ & $6 \mathrm{~m}$ & 1,05 & 1,05 & 0 \\
\hline
\end{tabular}

(Sumber: data primer yang diolah)

Berdasarkan pada data tabel diatas diketahui bahwa masih ada radiasi yang terukur setelah mengenai perisai radiasi, dengan kata lain terjadi kebocoran radiasi. Kebocoran radiasi tertinggi yang terukur adalah di titik pengukuran A yaitu kaca $\mathrm{Pb}$ di ruang operator yang berjarak 2,9 m dari sumber radiasi terukur sebesar 29,5 $\mu \mathrm{Sv} / \mathrm{h}$. Kebocoran radiasi tertinggi kedua adalah di titik pengukuran 1 yaitu pintu masuk pasien yang berjarak $5 \mathrm{~m}$ dari sumber radiasi terukur $0,35 \mu \mathrm{Sv} / \mathrm{h}$.

Hasil pengukuran laju paparan radiasi pada ruang CT-Scan di Instalasi Radiologi RSUD Ir. Soekarno Kabupaten Sukoharjo masih dalam batas aman atau tidak

Nilai laju paparan latar suatu daerah menurut United Nations Scientific Committee on the Effects of Atomic Radiation (UNSCEAR) berbeda-beda berdasarkan ketinggian lokasi daerah tersebut. Ketentuan nilai laju paparan latar suatu daerah menurut UNSCEAR untuk ketinggian 0 meter dari permukaan laut adalah $0.03 \mu \mathrm{Sv} / \mathrm{jam}$ dan untuk ketinggian 2000 meter dari permukaan laut adalah 0,1 $\mu$ Sv/jam. Lokasi RSUD Ir. Soekarno Kabupaten Sukoharjo terletak pada ketinggian 103 meter dari permukaan laut.

Paparan radiasi latar di Instalasi Radiologi RSUD Ir. Soekarno Kabupaten Sukoharjo termasuk dalam kategori 0 meter dari permukaan laut yang seharusnya memiliki laju dosis $0,03 \mu \mathrm{Sv} / \mathrm{jam}$. Hasil pengukuran laju paparan radiasi yang dilakukan pada ruang pemeriksaan CT-Scan di Instalasi Radiologi RSUD Ir. Soekarno Kabupaten Sukoharjo sebelum ekspose di dapatkan nilai rata-rata radiasi latar pada titik-titik pengukuran yaitu sebesar $1,225 \mu \mathrm{Gy} / \mathrm{jam}$.

Pada publikasi UNSCEAR nilai paparan latar suatu daerah memiliki satuan $\mu \mathrm{Sv} / \mathrm{jam}$ sedangkan pada hasil pengukuran memiliki satuan $\mu \mathrm{Gy} / \mathrm{jam}$, untuk membandingkan dengan ketentuan UNSCEAR maka satuan dari hasil pengukuran radiasi latar perlu dikonversikan dari Gy menjadi Sv,

$$
\begin{aligned}
& \text { yaitu: } \\
& 1 \mathrm{rad} \quad=1 \mathrm{cGy} \\
& 1 \mathrm{rem} \quad=1 \mathrm{cSv} \\
& 1 \mathrm{rad} \quad=1 \mathrm{rem}=1 / 100 \mathrm{~J} / \mathrm{kg} \\
& 1 / 100 \mathrm{~J} / \mathrm{kg}=1 \mathrm{cGy}=1 \mathrm{cSv} \ldots . .(10)
\end{aligned}
$$

Perhitungan di atas menunjukkan bahwa satuan Gy dengan Sv memiliki nilai sama. Maka dari hasil pengukuran tersebut diketahui bahwa nilai radiasi latar RSUD Ir. Soekarno Kabupaten Sukoharjo lebih tinggi dibandingkan dengan ketentuan nilai radiasi latar yang tercantum dalam publikasi UNSCEAR.

Hasil pengukuran laju paparan radiasi yang telah dilakukan pada ruang pemeriksaan CT-Scan di Instalasi Radiologi RSUD Ir. Soekarno Kabupaten Sukoharjo menunjukkan nilai laju paparan melebihi nilai radiasi latar (background) di beberapa titik pengukuran. Untuk mengetahui keamanan daerah di sekitar ruang pemeriksaan CT-Scan, maka hasil pengukuran laju paparan sebenarnya akan

\begin{tabular}{|c|c|c|c|c|}
\hline $\begin{array}{c}\text { Titik } \\
\text { pengukuran }\end{array}$ & $\begin{array}{c}\text { Hasil } \\
\text { ukur } \\
\text { sebenarn } \\
\text { ya } \\
(\mu \mathrm{Sv} / h)\end{array}$ & $\begin{array}{c}\text { faktor } \\
\text { hunian } \\
\text { (T) }\end{array}$ & $\begin{array}{c}\text { Hasil } \\
\text { dibagi } \\
\text { faktor } \\
\text { hunian } \\
\text { (T) }\end{array}$ & $\begin{array}{c}\text { Nilai } \\
\text { laju } \\
\text { paparan } \\
(\mu \mathrm{Sv} / \mathrm{h})\end{array}$ \\
\hline $\begin{array}{lr}\text { Pintu masuk } \\
\text { dari }\end{array}$ & 0 & 1 & $0: 1$ & 0 \\
\hline $\begin{array}{l}\text { Kaca } \mathrm{Pb} \text { di } \\
\text { Ruang operator } \\
\text { (A) }\end{array}$ & 29,5 & 1 & $29,5: 1$ & 29,5 \\
\hline $\begin{array}{l}\text { Kamar mandi } \\
\text { (B) }\end{array}$ & 0 & $1 / 5$ & $0: 1 / 5$ & 0 \\
\hline Ruang $\operatorname{arsip}(\mathrm{C})$ & 0 & $1 / 20$ & $0: 1 / 20$ & 0 \\
\hline $\begin{array}{l}\text { Pintu masuk } \\
\text { pasien (1) }\end{array}$ & 0,35 & $1 / 5$ & $0,35: 1 / 5$ & 1,75 \\
\hline $\begin{array}{l}\text { Ruang tunggu } \\
\text { pasien (D) }\end{array}$ & 0 & 1 & $0: 1$ & 0 \\
\hline
\end{tabular}
dibagi dengan faktor hunian (T) berdasarkan pada NCRP report no. 147. Faktor hunian menunjukkan lamanya seseorang berada di titik tersebut 
Tabel 4.3 Nilai laju paparan radiasi dengan memperhitungkan faktor hunian (T)

\begin{tabular}{|c|c|c|c|c|}
\hline $\begin{array}{c}\text { Titik } \\
\text { pengukuran }\end{array}$ & $\begin{array}{c}\text { Hasil } \\
\text { ukur } \\
\text { sebenar } \\
\text { nya } \\
(\mu \mathrm{Sv} / \mathrm{h})\end{array}$ & $\begin{array}{c}\text { faktor } \\
\text { hunian } \\
(\mathrm{T})\end{array}$ & $\begin{array}{c}\text { Hasil } \\
\text { dibagi } \\
\text { faktor } \\
\text { hunian } \\
\text { (T) }\end{array}$ & $\begin{array}{c}\text { Nilai } \\
\text { laju } \\
\text { papara } \\
\text { n } \\
\mu \mathrm{Sv} / \mathrm{h}\end{array}$ \\
\hline $\begin{array}{l}\text { Pintu masuk dari } \\
\text { ruang operator } \\
\text { (2) }\end{array}$ & 0 & 1 & $0: 1$ & 0 \\
\hline $\begin{array}{ll}\text { Kaca } & \mathrm{Pb} \text { di } \\
\text { Ruang } & \text { operator } \\
\text { (A) } & \end{array}$ & 29,5 & 1 & $29,5: 1$ & 29,5 \\
\hline $\begin{array}{l}\text { Kamar mandi } \\
\text { (B) }\end{array}$ & 0 & $1 / 5$ & $0: 1 / 5$ & 0 \\
\hline Ruang arsip (C) & 0 & $1 / 20$ & $0: 1 / 20$ & 0 \\
\hline $\begin{array}{l}\text { Pintu masuk } \\
\text { pasien (1) }\end{array}$ & 0,35 & $1 / 5$ & $\begin{array}{c}0,35: \\
1 / 5\end{array}$ & 1,75 \\
\hline $\begin{array}{l}\text { Ruang tunggu } \\
\text { pasien (D) }\end{array}$ & 0 & 1 & $0: 1$ & 0 \\
\hline
\end{tabular}

(Sumber: data primer yang diolah)

Setelah diketahui hasil pembagian dengan faktor hunian, maka nilai tersebut akan dibandingkan dengan NCRP report no. 147 tentang desain struktur pelindung untuk fasilitas kesehatan. Guna membatasi nilai paparan radiasi maka daerah okupansi dibagi menjadi daerah terkontrol dan daerah tidak terkontrol.

Hasil pengukuran laju paparan radiasi memiliki satuan $\mu \mathrm{Gy} / \mathrm{jam}$ yang setara dengan $\mu \mathrm{Sv} / \mathrm{jam}$, sedangkan NCRP report no. 147 nilai laju paparan yang diijinkan memiliki satuan mGy/jam. Untuk menyamakan satuan tersebut maka penulis mengkonversikan satuan $\mathrm{mGy} / \mathrm{jam}$ menjadi $\mu \mathrm{Sv} / \mathrm{jam}$,

yaitu :

$1 \mathrm{~mm}=103 \mu \mathrm{m}$

$1 \mu \mathrm{m}=1 / 1000 \mathrm{~mm}$

Tabel 4.4 Hasil konversi pengukuran laju paparan radiasi pada daerah terkontrol

\begin{tabular}{|c|c|c|c|c|c|}
\hline No & $\begin{array}{l}\text { Titik } \\
\text { penguku } \\
\text { ran }\end{array}$ & $\begin{array}{l}\text { Nilai } \\
\text { laju } \\
\text { paparan } \\
(\mu \mathrm{Sv} / \mathrm{h})\end{array}$ & $\begin{array}{l}\text { NCRP } \\
\text { Report } \\
\text { No.147 } \\
\text { DT } \\
(\mathrm{mGy} / \mathrm{h})\end{array}$ & $\begin{array}{l}\text { NCRP } \\
\text { Report } \\
\text { No.147 } \\
\text { DT } \\
(\mu \mathrm{Sv} / \mathrm{h})\end{array}$ & Ket \\
\hline 1. & $\begin{array}{l}\text { Kaca } \mathrm{Pb} \\
\text { di Ruang } \\
\text { operator } \\
\text { (A) }\end{array}$ & 29,5 & 0,0025 & 2,5 & $\begin{array}{l}\text { Tidak } \\
\text { aman }\end{array}$ \\
\hline 2. & $\begin{array}{l}\text { Pintu } \\
\text { masuk } \\
\text { dari } \\
\text { ruang } \\
\text { operator } \\
(2) \\
\end{array}$ & 0 & 0,0025 & 2,5 & Aman \\
\hline
\end{tabular}

(Sumber: Data primer yang diolah)
Tabel 4.5 Hasil konversi pengukuran laju paparan radiasi pada daerah tidak terkontrol

\begin{tabular}{|c|c|c|c|c|c|}
\hline No & $\begin{array}{l}\text { Titik } \\
\text { pengu- } \\
\text { kuran }\end{array}$ & $\begin{array}{l}\text { Nilai } \\
\text { laju } \\
\text { paparan } \\
(\mu \mathrm{Sv} / \mathrm{h})\end{array}$ & $\begin{array}{c}\text { NCRP } \\
\text { Report } \\
\text { No.147 } \\
\text { DTT } \\
(\mathrm{mGy} / \mathrm{h})\end{array}$ & $\begin{array}{l}\text { NCRP } \\
\text { Report } \\
\text { No.147 } \\
\text { DTT } \\
(\mu \text { Sv/h })\end{array}$ & Ket \\
\hline 1. & $\begin{array}{l}\text { Kamar } \\
\text { mandi } \\
\text { (B) }\end{array}$ & 0 & 0,0005 & 0,5 & $\underset{n}{\mathrm{Ama}}$ \\
\hline 2. & $\begin{array}{l}\text { Ruang } \\
\text { arsip } \\
\text { (C) }\end{array}$ & 0 & 0,0005 & 0,5 & $\underset{n}{\mathrm{Ama}}$ \\
\hline 3. & $\begin{array}{l}\text { Pintu } \\
\text { masuk } \\
\text { pasien } \\
\text { (1) }\end{array}$ & 1,75 & 0,0005 & 0,5 & $\begin{array}{c}\text { Tida } \\
\mathrm{k} \\
\text { aman }\end{array}$ \\
\hline 4. & $\begin{array}{l}\text { Ruang } \\
\text { tunggu } \\
\text { pasien } \\
\text { (D) }\end{array}$ & 0 & 0,0005 & 0,5 & $\underset{n}{A m a}$ \\
\hline
\end{tabular}

(Sumber: Data primer yang diolah)

\section{Hasil dan Pembahasan}

1. Prosedur pengukuran laju paparan radiasi pada Ruang CT-Scan di Instalasi Radiologi RSUD Ir. Soekarno Kabupaten Sukoharjo

Sebelum dilakukan pengukuran laju paparan radiasi pada daerah terkontrol dan daerah tidak terkontrol pada ruang pemeriksaan CT-Scan di Instalasi Radiologi RSUD Ir. Soekarno Kabupaten Sukoharjo penulis melakukan observasi secara langsung terhadap area ruang pemeriksaan CT-Scan yang meliputi pintu, dinding, kaca intip, ukuran ruang, lapisan $\mathrm{Pb}$, tanda radiasi, lampu indikator peringatan radiasi dan poster peringatan radiasi untuk ibu hamil dan menyusui.

Berdasarkan obervasi dokumentasi yang dilakukan penulis ukuran ruang pemeriksaan CTScan di Instalasi Radiologi RSUD Ir. Soekarno Kabupaten Sukoharjo yaitu Panjang $8 \mathrm{~m}$ lebar 4 meter dan tinggi $3,3 \mathrm{~m}$ desain ruangan tersebut sudah sesuai dengan standar ruangan radiologi berdasarkan PERKA BAPETEN No. 8 Tahun 2011. Karakteristik struktural ruang pemeriksaan CT-Scan di Instalasi Radiologi RSUD Ir. Soekarno Kabupaten Sukoharjo dindingnya terbuat dari bahan beton dengan ketebalan $30 \mathrm{~cm}$ dengan kaca intip di depan ruang operator yang mengandung bahan $\mathrm{Pb}$ dengan ketebalan $1,5 \mathrm{~mm}$.

Pada ruang pemeriksaan CT-Scan telah dilakukan pergantian pintu dan penutupan ventilasi dengan $\mathrm{Pb}$ setebal $2 \mathrm{~mm}$. Pintu tersebut awalnya merupakan pintu berdaun ganda yang menggunakan handle pintu bersekrup sehingga masih terdapat celah yang memungkinkan bocornya radiasi, pada bagian bawah pintu masuk utama yang telah diganti masih terlihat celah yang tidak tercover oleh tabir, diatas pintu utama 
terdapat lampu indikator bahaya radiasi akan tetapi tidak berfungsi, sehingga pada saat pelayanan pasien berlangsung lampu tersebut tidak menyala. Tidak adanya poster peringatan bahaya radiasi sebagai himbauan untuk ibu hamil dan menyusui.

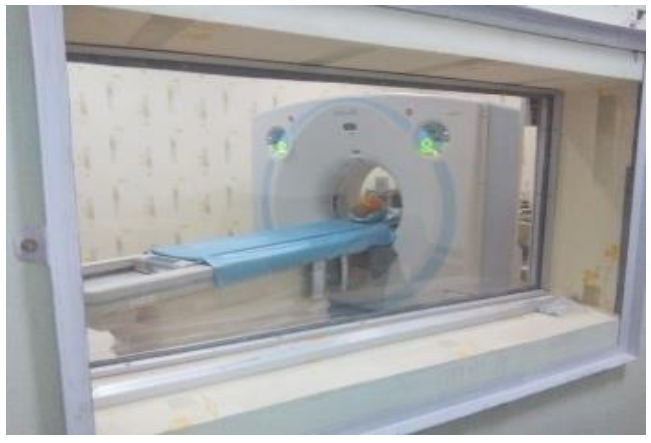

Gambar 4.13 kaca intip pada ruang operator yang mengandung $\mathrm{Pb}$ setebal $1,5 \mathrm{~mm}$

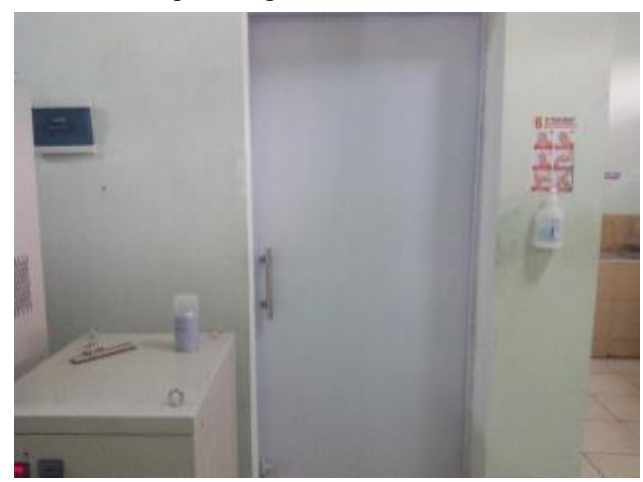

Gambar 4.14 pintu masuk ruang operator yang terbuat dari besi yang dilapisi dengan $\mathrm{Pb}$ setebal 2 $\mathrm{mm}$

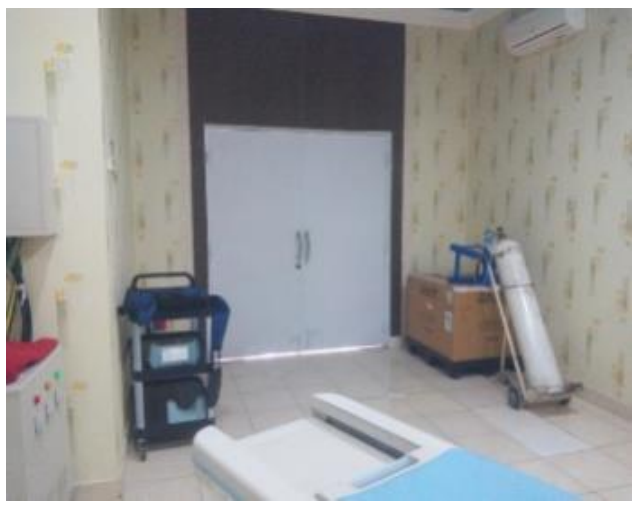

Gambar 4.15 pintu masuk utama tampak dari dalam

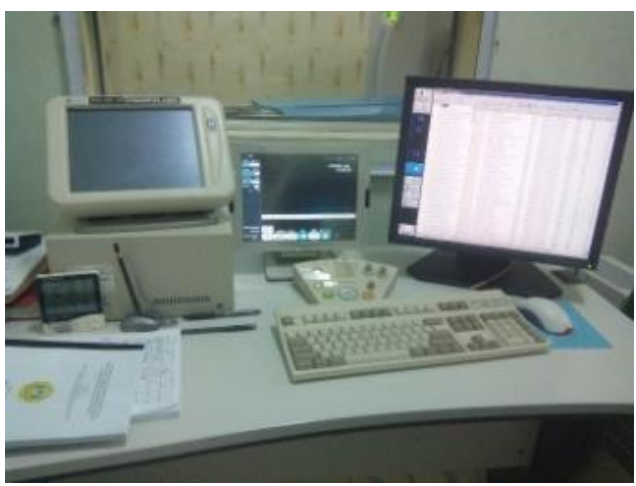

\section{Gambar 4.16 ruang operator}

Setelah melakukan observasi langsung, penulis melakukan pengecekan surveymeter babyline dengan mengecek kondisi baterai dalam keadaan baik atau tidak, pada pengukuran laju paparan radiasi ini penulis menggunakan skala alat ukur $100 \mu \mathrm{Gy} / \mathrm{jam}$ dan faktor kalibrasi sebesar 1,05, pada pengukuran laju paparan radiasi ini penulis menggunakan phantom kepala untuk mensimulasikan radiasi hambur pada saat ekspose, setelah mengatur posisi phantom penulis melakukan pengukuran laju paparan radiasi latar (background) di setiap titik yang sudah ditentukan sebelum dilakukan ekspose kemudian penulis mengatur scan parameter atau faktor ekspose. Faktor ekspose yang digunakan yaitu menggunakan scan parameter pemeriksaan kepala dengan besar $\mathrm{kV} 100$ dan mAs 200. Penulis melakukan pengukuran laju paparan pada titiktitik pengukuran yang telah ditentukan masingmasing sebanyak 3 kali.

2. Hasil pengukuran laju paparan radiasi pada Ruang CT-Scan di Instalasi Radiologi RSUD Ir. Soekarno Kabupaten Sukoharjo.

Paparan radiasi latar di Instalasi Radiologi RSUD Ir. Soekarno Kabupaten Sukoharjo termasuk dalam kategori 0 meter dari permukaan laut yang seharusnya memiliki laju dosis 0,03 $\mu \mathrm{Sv} / \mathrm{jam}$. Hasil pengukuran laju paparan radiasi yang dilakukan pada ruang pemeriksaan CT-Scan sebelum ekspose didapatkan nilai rata-rata radiasi latar pada titik-titik pengukuran tersebut yaitu sebesar $1,225 \mu \mathrm{Sv} / \mathrm{jam}$. Nilai laju paparan latar tertinggi yang terukur yaitu $2,1 \mu \mathrm{Sv} / \mathrm{jam}$ di titik A (kaca $\mathrm{Pb}$ di ruang operator) dan nilai terendahnya yaitu $1,05 \mu \mathrm{Sv} /$ jam di titik 2 (Pintu masuk dari ruang operator), titik 1 (Pintu masuk pasien) dan $\mathrm{D}$ (ruang tunggu pasien).

Nilai rata-rata dari laju paparan latar yang terukur menunjukkan bahwa nilai radiasi latar RSUD Ir. Soekarno Kabupaten Sukoharjo melebihi dari ketentuan nilai radiasi latar yang tercantum dalam publiksai UNSCEAR. Menurut penulis nilai radiasi latar yang terukur dapat berasal dari radiasi kosmik yang berasal dari luar angkasa atau luar atmosfer bumi dan radiasi primordial yang berasal dari mineral-mineral batuan dalam tanah.

Hasil pengukuran laju paparan radiasi saat dilakukan penyinaran sinar-X menunjukkan hasil yang bervariasi ada yang memiliki nilai yang sama dengan paparan latar dan ada juga yang melebihi nilai paparan latar atau terjadi kebocoran radiasi. Kebocoran radiasi tertinggi yang terukur adalah di titik $\mathrm{A}$ (kaca $\mathrm{Pb}$ di ruang operator) terukur sebesar 29,5 $\mu \mathrm{Sv} / \mathrm{jam}$, hal ini terjadi 
karena tabir perisai yang terdapat dalam bahan kaca di ruang operator terlalu rendah yaitu 1,5 $\mathrm{mm}$ timbal sehingga tidak dapat mengurangi radiasi hambur secara optimal. Kebocoran radiasi tertinggi kedua adalah di titik 1 (pintu masuk pasien) terukur sebesar $0,35 \mu \mathrm{Sv} / \mathrm{jam}$, hal ini terjadi karena desain pintu yang mengandung $\mathrm{Pb}$ tidak tumpang tindih sehingga masih terdapat celah pada bawah pintu yang mengakibatkan radiasi hambur masih dapat melewati daerah tersebut.

Hasil pengukuran laju paparan radiasi pada ruang CT-Scan di Instalasi Radiologi RSUD Ir. Soekarno Kabupaten Sukoharjo masih dalam batas aman atau tidak

Berdasarkan hasil pengukuran laju paparan radiasi yang telah dilakukan pada ruang pemeriksaan CT-Scan di Instalasi Radiologi RSUD Ir. Soekarno Kabupaten Sukoharjo, pada titik 2 (Pintu masuk dari ruang operator), B (Kamar mandi), C (ruang arsip), D (ruang tunggu pasien) tidak ditemukan adanya kebocoran paparan radiasi. Sedangkan pada titik pengukuran 1 (pintu masuk pasien) dan titik $\mathrm{A}$ (kaca $\mathrm{Pb}$ di ruang operator) ditemukan adanya kebocoran paparan radiasi. Untuk mengetahui keamanan dari ruang pemeriksaan CT-Scan, maka hasil pengukuran laju paparan sebenarnya akan dibandingkan dengan publikasi NCRP report no. 147 tentang desain struktur pelindung untuk fasilitas kesehatan. Titik $\mathrm{A}$ (kaca $\mathrm{Pb}$ di ruang operator) dan titik 2 (pintu masuk dari ruang operator) termasuk dalam daerah terkontrol yang memiliki nilai paparan radiasi yang diperbolehkan sebesar 2,5 $\mu \mathrm{Sv} / \mathrm{jam}$. Nilai laju paparan sebenarnya dititik A sebesar 0,0295 $\mu \mathrm{Sv} / \mathrm{jam}$. Nilai tersebut melampaui dari nilai laju paparan radiasi yang diperbolehkan menurut rekomendasi dari NRCP report no. 147 maka paparan radiasi yang terjadi di titik A (ruang operator) tidak aman bagi petugas dan masyarakat. Sedangkan pada titik 2 (pintu masuk dari ruang operator) menunjukkan nilai paparan radiasi 0 . Hal tersebut tidak melampaui dari nilai laju paparan radiasi yang diperbolehkan menurut publikasi NCRP report No. 147 maka paparan radiasi yang berada di titik 2 (pintu masuk dari ruang operator) aman bagi petugas dan masyarakat.

Titik 1 (pintu masuk pasien), B (kamar mandi), C (ruang arsip), D (ruang tunggu pasien) termasuk dalam daerah tidak terkontrol yang memiliki nilai paparan radiasi yang diperbolehkan sebesar $0,5 \mu \mathrm{Sv} /$ jam. Nilai laju paparan di titik B (kamar mandi), C (ruang arsip), D (ruang tunggu pasien) sebesar $0 \mathrm{mGy} / \mathrm{jam}$. Nilai tersebut tidak melampaui dari nilai laju paparan radiasi yang diperbolehkan dalam rekomendasi NRCP report no 147 menurut penulis, paparan radiasi pada titik B (kamar mandi), C (ruang arsip), D (ruang tunggu pasien) aman bagi petugas dan masyarakat. Sedangkan nilai laju paparan radiasi di titik 1 sebesar $0,00175 \mu \mathrm{Sv} / \mathrm{jam}$. Nilai tersebut lebih tinggi dari nilai laju paparan radiasi yang diperbolehkan dalam rekomendasi NCRP report no. 147 maka menurut penulis, paparan radiasi pada titik $\mathrm{E}$ tidak aman bagi petugas dan masyarakat

\section{Simpulan}

Pengukuran laju paparan radiasi pada ruang CT-Scan di Instalasi Radiologi RSUD Ir. Soekarno Kabupaten Sukoharjo menggunakan alat ukur surveymeter babyline dimulai dengan pengecekan baterai dan pemeriksaan sertifikat kalibrasi. Langkah-langkah pengukuran laju paparan radiasi antara lain mengukur jarak setiap titik terhadap sumber radiasi, melakukan pengukuran laju paparan radiasi latar (background),mengatur faktor ekspose dan melakukan pengukuran pada titik yang telah ditentukan sebelumnya sebanyak 3 kali disetiap titik.

Hasil pengukuran laju paparan radiasi di ruang pemeriksaan CT-Scan pada daerah terkontrol didapatkan nilai $29,5 \mu \mathrm{Sv} / \mathrm{jam}$, sedangkan pada pintu masuk dari ruang operator sebesar 0. Hasil pengukuran laju paparan radiasi pada daerah tidak terkontrol di pintu masuk pasien menunjukkan nilai sebesar $1,75 \mu \mathrm{Sv} / \mathrm{jam}$, sedangkan pada pintu masukdari ruang operator, kamar mandi, dan ruang arsip menunjukkan nilai 0 .

Berdasarkan publikasi NCRP report no 147 pada daerah terkontrol nilai yang diijinkan sebesar 2,5 $\mu \mathrm{Sv} /$ jam. Pada Kaca Pb di ruang operator menunjukkan nilai sebesar $29,5 \mu \mathrm{Sv} / \mathrm{jam}$, pada titik ini dinilai tidak aman bagi masyarakat dan pekerja radiasi. Berdasarkan hasil tersebut sebaiknya dilakukan penggantian kaca intip dengan ketebalan $2 \mathrm{~mm} \quad \mathrm{~Pb}$ dan dilakukan pengukuran laju paparan radiasi ulang. Pada pintu masuk dari ruang operator sebesar 0 $\mu \mathrm{Sv} / \mathrm{jam}$ dinilai aman bagi masyarakat dan pekerja radiasi.. Berdasarkan publikasi NCRP report no 147 pada daerah tidak terkontrol nilai yang diijinkan sebesar 0,5 $\mu \mathrm{Sv} / \mathrm{jam}$. Pada pintu masuk pasien menunjukkan nilai sebesar $1,75 \mu \mathrm{Sv} / \mathrm{jam}$, hal ini melebihi ketentuan dan dinilai tidak 
aman bagi masyarakat dan pekerja radiasi. Sebaiknya pintu selalu ditutup dan disediakan tabir $\mathrm{Pb}$ untuk menutupi celah yang terlihat pada bagian bawah pintu, serta dilakukan penambahan tanda peringatan bahaya radiasi untuk ibu hamil dan menyusui. Pada pintu masuk dari ruang operator, kamar mandi, ruang arsip dan ruang tunggu pasien menunjukkan nilai sebesar $0 \mu \mathrm{S} v /$ jam dinilai aman bagi masyarakat dan pekerja radiasi.

\section{Daftar Pustaka}

Akhadi, Mukhlis. 2000. Dasar - Dasar Proteksi Radiasi. PT. Rineka Cipta. Jakarta.

Batan. 2005. Pengenalan Radiasi. Pusdiklat Batan. www.batan.go.id diakses pada 20 Januari 2018 pukul 18.00.

Batan. 2009. Prinsip Dasar Pengukuran Radiasi. Pusdiklat Batan. www.batan.go.id diakses pada 19 Januari 2018 pukul 14.30.

Bapeten. 2011. Peraturan Kepala Badan Tenaga Nuklir Nomor 8 Tahun 2011 tentang Keselamatan Radiasi Dalam Penggunaan Pesawat sinar-X Radiologi Diagnostik dan Intervensional. Jakarta: Bapeten.

Bapeten. 2013. Peraturan kepala Badan Pengawas Tenaga Nuklir Nomor 4 Tahun 2013 tentang Proteksi dan Keselamatan Tenaga Nuklir. Jakarta: Bapeten.

National Council on Radiation Protection an Measurements. 2004. Report No. 147structural shielding Design for Medical X-ray Imaging Facilities. Bethesda: NCRP.

IAEA. Radiation Protection In Diagnostic And Interventional Radiology http://www.rpop.iaea.org/rpop/rpop/content/Do cument/TrainingRadiology/lectures/rpdir112_shielding.web Diakses pada 23 Januari 2018 pukul. 10.58 .

Rasad, Sjahriar. 2009. Radiologi Diagnostik Edisi Kedua. Jakarta: Balai Penerbit FK UI.

Sherer, MAS, Visconti, PJ \& Ritenour, ER. 2006. Radiation Protection In Medical Radiography. Canada: Mosby. Inc.

United Nations Scientific Committe of the Effects of Atomic Radiation. 2008. Sources,Effects and Risks of Ionizing Radiation. Volume I. United
Nations Scientific Committe on the Effects of Atomic Radiation. New York (S): UNSCEAR. 